\title{
Dante, Petrarca y Góngora en una despedida eviana*
}

\author{
Patrizia Di PATRE \\ Pontificia Universidad Católica del Ecuador \\ pdipatre@puce.edu.ec
}

A la memoria de Gloria Galli

\begin{abstract}
RESUMEN
En la original despedida de la canción A la muerte de Adonis, obra barroca del ecuatoriano Jacinto de Evia, hallamos una extraordinaria convergencia de pasajes dantescos, petrarquescos, gongorinos. Esta mezcla poética, obtenida a fuerza de un empirismo entusiasta, denuncia la versatilidad de módulos con un alto grado de utilización literaria -el imperativo dirigido a la canción, su metamorfosis en ave, la sucesión de sentencias en la clausura-, y posee además un fuerte interés intrínseco, como muestra del experimentalismo imperante en el ámbito específico del autor.
\end{abstract}

Palabras clave: Barroco hispanoamericano, Dante, Petrarca, Góngora, Jacinto de Evia.

\begin{abstract}
In the original farewell of the " canción de la muerte de Adonis", a baroque work by the Ecuadorian Jacinto De Evia we find an extraordinary convergence of passages based on Dante, Petrarca and Gongora's works. This poetic blending obtained by an enthusiastic empiricism shows the module changeableness, with a high level of literary use.

The imperative directed to the song - its metamorphosis into a bird, the succession of sentences at the end-, and possesses a strong intrinsic interest, as a sample of the experimentalism prevailing in the specific sphere of the author.
\end{abstract}

Keywords: Spanish America baroque, Dante, Petrarca, Góngora, Jacinto de Evia.

Sumario: I.1. Patente incongruencia, I.2. Tono sentencioso, II. Amor y muerte, III. Canción, ave de blancas plumas, IV. A raíz de la mezcla

* Trabajo realizado en el ámbito de un proyecto de investigación, con financiamiento de la Pontificia Universidad Católica del Ecuador. 


\section{I.1. Patente incongruencia}

Hay procedimientos poéticos que sorprenden, por lo versátil y superabundante de su industria creativa. Entre las composiciones del barroco ecuatoriano hallamos una canción más bien debilucha, indigna, diría, de su autor -Jacinto de Evia-, mas extremamente interesante desde una perspectiva crítica, debido a la fusión antiarmónica de motivos y a la escucha simultánea de autores diversos. Este final discordante de la canción A la muerte de Adonis reza así:

Canción, retarda el vuelo,
a los vicios no ultrajes tan atenta,
que su crueldad violenta
tronco te buscan para tu ruina,
¡qué dicha tan divina!,
que es de amantes morir con el amado
cuando el riesgo es mayor, más declarado. ${ }^{1}$

Primer dato chocante: se formula aquí, seguidamente y sin transición alguna, una decidida exhortación a la prudencia y la exaltada apología de su contrario, la "muerte por amor". Semejante lucha de imperativos antagónicos, en un mismo autor, no es nueva: pero pertenece a períodos distantes, evidencia fases no yuxtapuestas, sino temporal e ideológicamente espaciadas dentro de su aventura estética.

En Dante, por ejemplo, es muy evidente la evolución del principio descrito en piezas bastante alejadas entre sí. $\mathrm{Y}$ hay finales también ricos en contrastes ("Muéstrate a todos" / "No te muestres a nadie"; "Corre de prisa" / "Ve cauta"; "La venganza es un honor" / "El perdonar es noble", etc. ${ }^{2}$ ); pero lo que predomina en ellos, o en su consideración crítica, es la medida de una maduración progresiva, de un ascenso calculado. Darán fe de ello los extremos representados por canciones como La dispietata mente ${ }^{3}$, presumiblemente de época temprana, con su patética amonestación conclusiva ("Canzone, il tuo cammin vuol esser corto"), y la sublime y "postrera", podríamos decir, del exilio ${ }^{4}$ ("lo dolce pome a tutta gente niega"); y hay

${ }^{1}$ Citamos según la versión elaborada por A. Carrión (1992), p.102.

${ }^{2}$ Confróntese el antagonismo de los siguientes versos en las canciones dantescas que enunciamos a continuación: "Io parlerò di voi in ciascun lato" (Amor, che ne la mente: Conv. III, v. 90); "Canzone, a' panni tuoi non ponga uom mano" (Tre donne, Rime, 47, v. 91); "Che ti merranno là per via tostana"(Vita Nuova, XIX, 14, v.68); "Però ti prego che tu t'assottigli, / dolce mia amorosa, / in prender modo e via che ti stea bene" (Io sento si d'Amor: Rime, 38, vv. 84-6); "Ché bell'onor s'acquista in far vendetta" (Cosi nel mio parlar: Rime, 46, v. 83); y, finalmente, la fatídica máxima de Tre donne: "Che'l perdonare è bel vincer di guerra" (v.107). Citamos respectivamente de: Dante Alighieri, Il Convivio (1966), p.72; Rime (1946), pp.174; 132; 167; 175; Vita Nuova (1980), 128.

${ }^{3}$ D. Alighieri, Rime (1946), 7, pp. 46-9.

${ }^{4}$ Tre donne. 
naturalmente toda una red intermedia de reticencias y largas concesiones, de afanes templados y angustia presurosa ${ }^{5}$. Nunca un brusco injerto de arlequinescos retazos.

La producción gongorina (más allá de un Petrarca que se limita a discurrir consigo mismo, o pone límites fijos a la aparición de su criatura poética ${ }^{6}$ ) registra los mismos cánones. Hay una distancia insalvable entre la exhortación al repliegue honesto ${ }^{7}$, que es todo un "recogerse" del alma ("Canción, di al pensamiento que corra la cortina" ${ }^{8}$ ), y la orden juvenil de lanzarse al espacio exterior; con la sucesiva conversión de algo tan íntimo como el pensamiento en un ser alado prodigioso: "Vuela, pensamiento, y dile a los ojos que te envío, que eres mío" 9 .

Jacinto de Evia prefiere al parecer un resbalón súbito; no se limita a la superposición de rasgos estilísticos, sino que hace chocar actitudes anímicas opuestas. Veremos seguidamente cómo el contraste a lo Stevenson se prolonga en la serie de motivos, figuraciones y, por supuesto, en las propias fuentes de la inspiración eviana.

\section{I.2. Tono sentencioso}

La despedida de Adonis -en la persona ficticia de un interlocutor prudentecontempla dos sentencias clarísimas:

a. [...] que su [de los vicios] crueldad violenta tronco te buscan para tu ruina.

b. que es de amantes morir con el amado / cuando el riesgo es mayor, más declarado.

A la primera, precedida del omnipresente conectivo causal, asigna su valor admonitorio una constatación de fácil y reconocida generalidad -tal es siempre en efecto el valor de un lema-. La segunda encuentra seguro apoyo en la tradición de las rimas amorosas, y aquí habrá que detenerse algún tanto. Esta tendencia a amonestar en rima es, de todos modos, asaz límpida, y coincide obviamente con el sitio compositivo más apto para la reflexión, o sea la solemne despedida. Veamos primeramente el factor en cuestión.

Entre la nutrida sucesión dantesca de finales sentenciosos, hay uno que parece cercano al nuestro, esencialmente por contigüidad temática. Se trata de la segunda despedida a la canción Io sento sì d'amor, la cual finaliza de este modo:

"Canzone, a' tre men rei di nostra terra / te n'anderai [...]; Digli che 'l buon col buon non prende guerra, prima che co' malvagi vincer prove; / digli ch'è folle chi non si rimove / per tema di vergogna da follia: / ché que' la teme ch'ha del mal paura, / perché, fuggendo l'un, l'altro assicura".

${ }^{5}$ Cfr. nota 2; y los ejemplos podrían multiplicarse.

${ }^{6}$ Véase Cancionero, L, 74: "Mostrarte no querrás en cualquier sitio"; y CXXV,81: "Quédate en estos bosques". En Petrarca (1989), pp. 261; 453.

${ }^{7}$ Como en Corcilla temerosa: "Quédate aquí, canción, y pon silencio / al fugitivo canto;/ que razón es parar quien corrió tanto". Góngora (1943), pp. 486-88 (Canción, 384).

${ }^{8}$ Cfr. Qué de invidiosos montes. Góngora (1943), pp. 493-94( 388).

${ }^{9}$ En Letrillas, 105, pp. 248-9. 
Anteriormente, y como fruto de la primera despedida, encontramos los siguientes versos:

“Ché 'l buon col buon sempre camera tiene [...]. Con rei non star né a cerchio né ad arte, / ché non fu mai saver tener lor parte" ${ }^{10}$.

Tres sentencias seguidas, con otras tantas exhortaciones a la prudencia en el trato con los amigos; se deben escoger los buenos, dejando a los otros que vaquen a su propia suerte. Tenemos ya cierto parecido con el peligro vislumbrado en la canción eviana, el daño procedente de la maldad. Pero el factor de mayor interés está en la serie de sentencias, que clausuran con tono sabio nuestra pieza poética.

Otras despedidas dantescas se acercan más al acento del ejemplar eviano: como la petrosa de Così nel mio parlar, la cual reza valientemente: "ché bell'onor s'acquista in far vendetta" ". En Tre donne la entonación no es menos decidida, aunque con referente invertido:

"Camera di perdon savio uom non serra, ché 'l perdonare è bel vincer di guerra" 12 .

El esquema está bien claro: orden perentoria, apoyada en un enunciado grave, epideiktikós.

Tal mecanismo parece más propio de los italianos que de sus émulos españoles: en Góngora se encuentra apenas (a menos que no queramos considerar como sentenciosa la leve anotación de Corcilla temerosa ${ }^{13}$ : "Que razón es parar quien corrió tanto"). Mientras que la poesía de Petrarca abunda en constataciones enfáticas de este tipo:

"Que hay más gloria en el reino de los cielos / por uno convertido, y más se estima, / que por noventa y nueve de los justos" 14 .

“Ahora vete, y no pierdas a las otras, / que no solo en las vendas / se alberga amor, por quien se ríe y llora" 15 .

${ }^{10}$ Para obtener alguna referencia sobre la tradición española temprana de estas rimas morales, podría verse P. Di Patre (2007).

${ }_{11}^{11}$ Io sento si, respectivamente vv. 97-8; 101-6.

12 Vv. 106-7. Se podría añadir aquí la canción filosófica Doglia mi reca, llena de sentencias y máximas morales : "ché l'amorose fronde / di radice di ben altro ben tira" (vv. 134-5); "ché rado sotto benda / parola oscura giugne ad intelletto" (vv. 57-8), etc.

13 L. de Góngora (1943), 384.

${ }^{14}$ F. Petrarca (1989), XXVI, vv.12-4. Preferimos citar las rimas de Petrarca en español, debido a su frecuentación asidua por parte de los escritores barrocos, incluyendo a nuestro autor de referencia -Jacinto de Evia-, y también por la mayor aproximación que, de este modo, se instaura.

${ }^{15}$ Canc., XXVIII (Oh esperada en el cielo), 112-4. 
Estos son ciertamente ejemplos significativos, y que pueden esclarecer el final de Evia considerado; mas hay que llegar al apéndice del soneto CXL, con un característico cruce de motivos análogos, para apreciar su virtual trascendencia para con el epígono de la Colonia. Lo veremos más adelante. Por el momento importa resaltar la persistencia de la conjunción señalada (imperativo y moraleja), la cual nos da el sello del módulo estilístico. En el momento en que intervenga un motivo más específico -y aquí tenemos uno de cálida poesía-, el bloque considerado se convertirá en la criatura detallada de Evia, remitirá al ejemplo ilustre de Petrarca: al cual dedicaremos la sección siguiente.

\section{Amor y muerte}

La advertencia final de la despedida eviana evoca un cuadro "sabroso", diría santa Teresa, típico de la tradición amorosa sacra y profana. Tal vez se deba a esto la extraña colisión ya verificada, ese tránsito inesperado de pensamientos mixtos en un carril restringido. La idea que se perfila en el horizonte -amor mortífero, un peligro constante- produce por asociación la nostalgia de lo funéreo ligado a la defunción, el espectro del exceso sentimental.

Una enseñanza poética de la mística: a la unión íntima de las almas le corresponde una incineración absoluta ${ }^{16}$ : "haciendo porque mueras / las flechas que recibes" ${ }^{17}$. Aquí la muerte es el fin deseado de un proceso aún imperfecto, sin ella:
¿Por qué, pues has llagado
aqueste corazón, no le sanaste?
Y pues me le has robado, ¿por qué así le dejaste, y no tomas el robo que robaste? ${ }^{18}$

"Muero, porque no muero", dirá la santa avilesa ${ }^{19}$. "Mas, ¿cómo perseveras, oh vida, no viviendo donde vives [...]?", insiste en los versos del Cántico espiritual (367) el propio Juan. Puesto que "de Ti me van mil gracias refiriendo, / y todos más me llagan, / y déjame muriendo / un no sé qué que quedan balbuciendo" (ibid., 32-5). Cuando se apaga la candela de una vida accesoria, con progreso invertido, y llega la entropía absoluta de la materia, se enciende por fin la verdadera luz espiritual, que "a vida eterna sabe, / y toda deuda paga [...]. Matando, muerte en vida la has trocado" ${ }^{20}$.

Muy bien. Autores como Jacinto de Evia oscilan constantemente entre las flores del laicismo barroco y un fuego místico aún más deleitoso. Estoy convencida de que la brusca interrupción del canal semántico en este -un poco enajenado, hay que

${ }^{16}$ Este y otros conceptos afines en P. Di Patre y M. Mafla (2009). Y se podría remitir también a P. Di Patre: "Conocimiento y experiencia" (2009).

${ }^{17}$ Cántico espiritual, v. 38-9. En J. de la Cruz (1988), p.63.

${ }^{18}$ Ibid., vv. 41-5.

${ }^{19}$ T. de Jesús (1967), pp. 499-500.

${ }^{20}$ Llama de amor viva, vv. 10-12. J.de la Cruz (1988), p.76. 
admitirlo, de esquizofrénica poesía- excéntrico final eviano obedece ante todo al estímulo de imágenes cruzadas, de pronto convergentes e inextricables.

Otro filón en la maraña descrita. El modelo petrarquesco ofrece un ejemplar sublimado de amor mortal. Abundan en el cantor de Laura las ideas prerrománticas ligadas al final fatal, previsto en forma casi liberatoria. También el Dante joven nos ofrecía un cuadro parecido, en rimas como La dispietata mente o Lo doloroso amor, que culminaba así : "Fin a la morte mia sospira e dice: / Per quella moro ch'ha nome Beatrice" (Rime, 21, 13-4). Y el mismo prototipo gongorino habla de ello con abundancia ${ }^{21}$. Pero Petrarca no brinda solo pintura, sino que distribuye los colores y enseña la pincelada exacta. Mírese cómo trabaja en LXXXVI: "Ch'è bel morir, mentre la vita è dextra" (v. 4). Lo bueno es que se logra respetar la sentencia. Y en LIX (vv.16-7) nuestro autor insiste: "Ni por dolor o muerte / quiero que Amor me libre de tal nudo".

Sí, pero no tenemos aún el molde perfecto de nuestro verso eviano, el inconsecuente "que es de amantes morir con el amado", sentencioso y solemne en su desesperación calculada. Lo hallamos sin embargo en otra composición cercana, el emblemático soneto CXL. Allí se exclama a manera de conclusión: "que buen fin halla quien amando muere", fuente indiscutible de nuestro fragmento colonial.

\section{Canción, ave de blancas plumas}

A los poetas les gusta generalmente representarse sus propios pensamientos en forma alada, como seres etéreos totalmente librados de las amarras terrenales. Homero enseña. Y Safo aprovecha la tradición, sustituyendo el águila por los gorriones, en búsqueda perpetua de una forma antimarcial, totalmente íntima ${ }^{22}$.

A Góngora le encanta esta manera: continuamente alude a criaturas -cerebrales o no- dotadas de alas, creando así todo un mundo de plumíferos objetos, emanación inmaterial del poeta o materialización brumosa de un universo inconsistente, al cual urge conferir la apariencia de un reflejo platónico. Sus figuraciones no tienen nunca contornos nítidos, y asemejan ora a la inestable onda, ora a la fugitiva aurora $\mathrm{o}$, todavía mejor, a la saeta sin nombre, por el traspaso fulminante aun en el reino de las esencias.

Petrarca es distinto: él mismo se vuelve pájaro, el albatros maldito e inadaptado de eterna memoria:

Canción, jamás de oro fui la nube que luego descendió en preciosa lluvia y que en parte apagó de Jove el fuego; que más fui llama de un mirar hermoso, y el pájaro que más subió en el aire, alzando a la que alabo en mis palabras (Canc. XXIII, 161-6).

${ }^{21}$ Para lo cual, véase P. Di Patre: "Góngora, Jacinto de Evia” (2009).

${ }^{22}$ Cfr. sobre el argumento los trabajos ya clásicos del que me gusta recordar como mi profesor de literatura griega en la Universidad de Pisa, V. Di Benedetto (1973), pp. 121-3. 
El águila como poeta de elegantes versos es figuración dantesca: véase cómo en el De Vulgari Eloquentia (II, IV, 11) el maestro traza la imagen del sublime versificador, y satiriza al mismo tiempo su contrario:

Et ideo confutetur illorum stultitia qui, arte scientiaque immunes, de solo ingenio confidentes, ad summa summe canenda prorumpunt; et a tanta presumptuositate desistant, et si anseres natura vel desidia sunt, nolint astripetam aquilam imitari.

Quien puede pintar así al artífice de versos, haciendo que se parezca alternativamente al "uccel di Giove" y a un ganso; quien sienta una pasión tan irresistible por el halcón, los lebreles y la rápida caza ${ }^{23}$, no es de extrañar que produzca luego un final concebido en estos términos:

Canzone, uccella con le bianche penne, canzone, caccia con li veri veltri, che fuggir mi convenne, ma far mi poterian di pace dono (Tre donne, 101-4).

Increíble despedida metafórica, porque dotada de una energía física incalculable. Los negros lebreles y las blancas plumas no son sino equivalentes simbólicos de las facciones florentinas, la una blanca, la otra negra. La apelación es a un perdón absoluto, bajo el prisma sin colores de una luz esencial:

Camera di perdon savio uom non serra, ché perdonare è bel vincer di guerra (106-7).

"Canción", dirá a su vez Jacinto de Evia, "retarda el vuelo: que es de amantes morir con el amado cuando el riesgo es mayor, más declarado". Su ave canora no desplegará las alas: tiene que recogerlas, reservando para el postrer final el amoroso despunte del águila.

\section{A raíz de la mezcla}

Hemos podido constatar que de todas las sugestiones anteriores, sapientemente cribadas por el experto artífice, lo único en sobrevivir es la solidez del esquema -presente en todos los autores considerados-; la constancia de una figuración simbólica; el inevitable desemboque pronosticado por místicos y amantes al confluente copioso del eterno mar, al Amor en suma, infeliz o felizmente muerto.

Pero esto no basta, no es suficiente para definir el aura polifacética de la canción, cierto empirismo entusiasta, como de botica en plena actividad. Un análisis minucioso adscribe a tal heterogeneidad, aparentemente programática, un origen involuntario.

${ }^{23}$ Véase el soneto juvenil Sonar bracchetti, 15. En D. Alighieri, Rime (1946), pp.64-5. Con relación al arte dantesco en la fase temprana de las Rimas, cfr. el ejemplar estudio de G. Contini (1960). 
Tenemos como resultado indiscutible una simple evocación de versos dantescos, en especial los que conforman la canción del exilio; pero se trata de rimas célebres, poéticamente recicladas en el ambiente de discípulos luego convertidos en maestros universales: maestros también de Evia.

Que esto sea así, se demuestra fácilmente procediendo a una buena organización de los componentes primarios. Tres, como vimos anteriormente, es decir:

\section{a. Imperativo dirigido a la canción}

Hay aquí una integración absoluta entre el receptor del mensaje y quien lo formula: el autor se identifica totalmente con el portador material de su embajada. Cfr. en Tre donne la invitación a una militancia estratégicamente neutra: "Canción, ave de blancas plumas; canción, caza con los negros lebreles", compartida con la pieza poética al igual que la advertencia prudente de Evia. Este procedimiento se encuentra también, por supuesto, en la obra gongorina: "Canción, di al pensamiento que corra la cortina" (63); "Quédate aquí, canción, y pon silencio al fugitivo canto: que razón es parar quien corrió tanto" (384). Bien difícil sería reconocer allí la identidad de los agentes, desembrollar la madeja de abstracciones biológicas y anímicas. La canción se funde con su autor, todo resulta lo mismo. Pero la fuente de ello es Dante; él da la manera y distribuye posibilidades. Jacinto de Evia lo imita en su canción directamente, en concomitancia con otros factores.

\section{b. Metamorfosis en ave}

Peculiarmente dantesca, esta imagen se retoma de modo puntual, bajo la forma de un predicado aristotélico: la posibilidad de retardar el vuelo atañe a su esencia fundamental, así como en Dante la invitación a "uccellare", que no es sino la actuación de los pájaros, en una ostentación simbólica de blancas plumas.

\section{c. Sucesión de sentencias}

Es este a mi parecer el componente más exclusivo, y por ende emblemático, de la operación considerada. Confróntense los versos pertenecientes a despedidas, respectivamente, dantesca y eviana:

Canzone, uccella con le bianche penne;

canzone, caccia con li neri veltri,

che fuggir mi convenne,

ma far mi poterian di pace dono.

Però nol fan che non san quel che sono:

camera di perdon savio uom non serra,

ché 'l perdonare è bel vincer di guerra (Tre donne, 101-7).

Canción, retarda el vuelo,

a los vicios no ultrajes tan atenta

que su crueldad violenta

tronco te buscan para tu ruina,

¡qué dicha tan divina!, 
que es de amantes morir con el amado cuando el riesgo es mayor, más declarado (A la muerte de Adonis, 53-9).

Con una estructura idéntica (dos sentencias seguidas, y un oportuno anuncio conectival; imperativo en el exordio), a más de un tono moralizador parecido, ambos autores subrayan en forma, respectivamente, positiva y negativa, la oportunidad y consecuencia de cierto comportamiento. Hasta parecería que la exclamación eviana, ausente en el ejemplar dantesco, se haya insertado con la finalidad expresa de reunir tres partículas homólogas (ché $=$ que), como en el patrón histórico.

Pero el final es todo petrarquesco. El detalle indica que la visión de Dante tiene, en la poesía eviana, una fuerte proyección al futuro. La misma incongruencia del texto patentiza la superficialidad del proceso mnemónico en acto, casi una fantasía de recuerdos no interiorizados. Nuestro autor se encuentra divagando, y no distingue claramente (salvo el trayecto esencial) entre el Dante genuino y su utilización en lengua española.

Semejante "bazar" de ideas poéticas podría no convencer; pero lo que muestra: un ideal collage de elementos diversos, de procedencia variada, posee un alto interés científico, como muestra de laboratorio y detalle experimental. Esta vez el esqueleto poético se muestra al desnudo: filológicamente, no queda nada por hacer.

\section{OBRAS CITADAS}

\section{Ediciones}

CARRIÓN, Alejandro: Antología general de la poesía ecuatoriana durante la colonia española, Quito, Grafiesa, 1992.

Dante ALIGHIERI: Il Convivio. Edizione critica a cura di Maria Simonelli. Bologna, Pàtron, 1966.

--- De Vulgari Eloquentia. A cura di Pier Vincenzo Mengaldo. In D.A. Opere Minori. Milano-Napoli, Ricciardi, 1979. Tomo II, pp. 3-237.

---. Rime. A cura di Gianfranco Contini. Torino, Einaudi, 1946.

---. Vita Nuova. A cura di Domenico De Robertis. Milano-Napoli, Ricciardi, 1980.

Francesco PETRARCA: Cancionero. Texto establecido por Gianfranco Contini; Traducción y notas de Jacobo Cortines. Madrid, Cátedra, 1989.

Luis de GÓNGORA Y ARGOTE. Obras completas. MILLÉ y GIMÉNEZ, Juan; MILLÉ y GIMÉNEZ, Isabel eds. Madrid, Aguilar, 1943.

San JUAN DE LA CRUZ: Obras, Madrid, Editorial de Espiritualidad, 1988.

Santa TERESA DE JESÚS. Obras completas, Madrid, Biblioteca de Autores Cristianos, 1967.

\section{Estudios}

CONTINI, Gianfranco: Poeti del Duecento, Milano-Napoli, Ricciardi, 1960. DI BENEDETTO, Vincenzo: "Il volo di Afrodite in Omero e in Saffo", QUCC, XVI (1973), pp. 121-3. 
DI PATRE, Patrizia: "Dante 'minore' nella Spagna del Quattrocento". En Actas del I Congreso Andino de Estudios Dantescos. Revista FISMAT, n. 16 (2007), www.ciencias.epn.edu.ec

---: "Conocimiento y experiencia en la dimensión mística. Rogelio Bacon y Jacinto de Evia”, Ciencia Tomista, 136 (2009),438, pp. 101-122.

--: “Góngora, Jacinto de Evia y la 'Virgen del Panecillo' en Quito", Anales de Literatura Hispanoamericana, XXXVIII (2009), pp. 307-20.

DI PATRE, Patrizia - MAFLA, Mercedes: "Disolución de patrones épico-amorosos en la poesía ecuatoriana tardobarroca", Revista Espéculo, n. 40, http://www.ucm.es/info/especulo/numero40/poecuato.html. 